in sanatoriums more efficient means are adopted for the destruction of tubercle bacilli than in ordinary bouses. The principles of careful disinfection are not readily taken up by the public and one of the many virtues of the sanatorium method of treatment is that it helps to educate people in this respect. I refrain in consideration of your space from going into further detail, but if your correspondent is still unconvinced I would refer him to the original papers on this subject and to Dr. Rufenacht Walters's and others' books on sanatoriums.

Mr. Marriott reiterates his statement that isolation fever hospitals breed secondary infection and post-scarlatinal diphtheria, and that therefore sanatoriums for consumption must be responsible for something of the same kind. He is convinced of this because " secondary infection and post-scarlatinal diphtheria never obtain in ordinary houses." Your correspondent's experience must have been a singularly fortunate one, for it is no uncommon thing in London to see children who have fallen victims to secondary infection or diphtheria after an attack of scarlet fever, although they have been treated in their own homes. I should like to say more concerning these isolation hospitals, but this question is somewhat beside the point. An a priori line of argument is seldom convincing, and it would be more satisfactory if $\mathrm{Mr}$. Marriott brought forward instances of secondary infection which have occurred in sanatoriums for tuberculosis. If such cases have occurred he should have no difficulty in producing them, seeing that this form of treatment has been in existence for 40 years.

Your correspondent further asserts that the personal factor of a patient cannot receive the same attention in a sanatorium as at home. Is this in accordance with fact? At an efficient institution of this kind each patient is seen professionally at least three times a day, and also takes his meals under the immediate supervision of the physician. In addition to this, every detail of his life, such as the amount of exercise he may take, the literature he may read, and the like, receives the most anxious and painstaking consideration. It is this careful attention to an infinity of detail which is one of the most characteristic features of sanatorium treatment; it is more essential than the nature of the building, but I can see no reason why Mr. Marriott, who champions good sanitation, should object to the institution being made as healthy as possible. The necessary discipline of such treatment as the above cannot in the nature of things be carried out at home until the patient's disease has become quiescent and he has learnt the true value of its details. 40 years' experience has shown that when the attempt is made to treat a case from the first at home it not infrequently fails.

Dr. Walther, who prefers severe cases, brings about arrest of the disease in 30 per cent. (Knopf) of his patients, and these continue to do well after they have left the Nordrach Colonie. He only fails to obtain considerable improvement in 5 per cent. of his cases, and his world-wide reputation, to which your correspondent refers, is due to the enormous amount of attention he devotes to the personal factor of his patients. Other efficient sanatoriums give equally satisfactory results. Can Mr. Marriott show anything to equal these figures by home treatment in all stages of the disease?

No one will deny that good sanitation is the best weapon we have for the prevention of tuberculosis and is largely responsible for the diminution in the mortality from this disease in the last 60 years, a period which coincides, as Dr. J. E. Pollock has pointed out, with the time during which the Brompton Hospital has been in existence. I cannot, however, agree with Mr. Marriott that in treating those already afflicted with the disease we should deny them the form of treatment which on 40 odd years' experience has been shown, not, it is true, to cure every case, but to be the best with which we are acquainted.

Brook-street, W., Jan. 29th, 1902.

\section{IS S.ALT A PROBABLE CAUSE OF CANCER?}

To the Elditors of THE LANCET.

Sins, - The letter of Mr. R. D'Oyly Noble in THE LANCET of Jan. 25th, p. 261, is founded upon an assertion which I think is incorrect. Having admitted that $I$ have con. clusively proved in my paper upon this subject, a short abstract of which was published in THE LANCET of Dec. 7th, 1901, p. 1578, that in those sections of the country in which a very large amount of bacon and ham is consumed, as in the Malton and Pickering cancer field, the disease of cancer is most prevalent, he suggests that the cause is not an excessive amount of salt consumedalong with, I suppose, an unnecessary amount of animal foodbut that it is owing to the bacon or ham being itself unclean owing to American pigs being habitually fed on the entrails and blood of slaughtered animals, many of which are infected by diseases of a cancerous nature. I think this is a gross libel upon the Americans ; but even if it were true-which it cannot be, for they rear their own pigs-there would be no harm in letting pigs eat the entrails of slaughtered animals. It is not a nice idea, but hens are commonly given in this country chopped sheep's entrails. Nothing is found to make them lay eggs better and neither the eggs nor the hens are infected from the food. We manure our corn with the most offensive dung, but the wheat is quite pure. In growing celery the dung comes into close contact with the plants and they are not injured thereby. We ourselves habitually eat semi-putrid game, previously cooked I admit, but it cannot be called clean food for all that. I do not believe for a moment that the diseases of a cancerous nature spoken of are such-and, moreover, if the pigs eat the entrails, who eats the cancerous meat?

If I could persuade the Editors of THE LANCET to publish my paper in full some misconceptions about it would disappear, especially that I founded the theory in any way upon the comparative immunity of the Jews from cancer. I merely mentioned this as one of three points which first drew my attention to the subject, and after further investigation, although it has confirmed the opinion that Jewesses are almost exempt from cancer of the uterus and that Jews are less liable to cancer generally than we are, I now doubt whether this has any connexion with the ingestion of salt Whether, however, this is so or not does not affect my argument in the least, as it was not founded upon it.

What I complain of in the present ideas about the investigation of cancer is that so-called committees are suggested and money is asked for to make further researches when the materials are already at hand to come to a pretty definite conclusion Almost hundreds of facts are known about the disease, but these facts are not utilised by comparing one with another. A criminal is being looked for who is destroying our population in a most deadly and painful manner. Why not see what circumstance or object is common to all cases of cancer? This is precisely how a detective would set to work in a criminal investigation. If in a number of burglaries a certain man could be proved to be invariably close to the spot in every instance, although not actually seen to do the deed, I think almost any jury would convict him. My point is, that whenever cancer exists two at least of four factors must be present. One of these is salt in some excess, the other is a local irritant. Of the other two factors-viz., over-feeding and effeteness-one is usually present, but not necessarily. I think that a small amount of salt is necessary to health, but if taken in the large amount it usually is, along with a good deal of meat, it is dangerous as age adrances, and highly dangerous if the life is an indolent one and passed much indoors. On the other band, I think salt quite inoperative unless with the coöperation of some local irritant, such as the sharp edge of a stump in the mouth or an unglazed tobacco-pipe. There is one most remarkable instance of a local irritant mentioned in my full paper. The natives of Cashmere carry a small brazier of hot coals pressed against the skin of the abdomen to keep themselves warm in lieu of sufficient clothing in winter. This causes cancer of the skin. They take a large amount of salt, and salt, rice, peas, and wheat are the only things common to them and to us ; everything else in food and general environment is different. II am, Sirs, yours faithfully,

Leeds, Jan. 24th, 1902.

JAMES BRAITHWAITE.

\section{SECOND ATTACKS OF SMALL-POX. To the Editors of THE LANCET.}

SIRS,-In support of your remarks in THE LANCET of Jan. 25th, p. 248, on this subject, I may say that recently one of my sanitary inspectors said that he did not think that he need be revaccinated as he had had small-pox and had been kept from work for three months in consequence. As his face was unscarred I questioned him as to symptoms, distribution of eruption, \&c., and came to the conclusion that his supposed attack of small. pox had been one of chicken-pox. This opinion was 
strengthened by the fact that vaccination ran an ordinary course. I suspect that not a few people who think themselves immune through having already had an attack of small-pox are buoying themselves up with a false belief, having had chicken-pox and not small-pox. The only means of obtaining any degree of assurance as to immunity to small-pox is to submit to vaccination and see the result. I am, Sirs, yours faithfully,

J. T. C. NAsH, M.D. Edin., D.P.H. Cantab., Medical Officer of Health.

Southend-on-Sea, Jan. 28th, 1902.

\section{FIRST AID FOR PRIMARY HÆMORRHAGE THE WRONG INSTRUCTION GIVEN TO AMBULANCE CLASSES. \\ To the Editors of THE LANCET.}

SIRs, - I have read with the greatest gratification the leading article in THE LANCET of Jan. 25th, p. 238, and as I have been connected with the ambulance movement ever since its commencement I can thoroughly endorse all you say. The teaching of the St. John Ambulance Association is excellent in every way and the treatment of hæmorrhage, the most important of all matters which the first-aid student has to deal with, is thoroughly taught. The efficiency of the men in the St. John Ambulance Brigade is tested annually and no man is allowed on duty in the streets of London except those who have passed the re-qualifying examination; so the general public may know that in the men of this brigade they have those upon whom they can thoroughly rely. With the general public who hold certificates of ambulance work, however, no such precaution is taken ; they attend ambulance lectures and afterwards fail to keep up their knowledge, and relying upon the fact of having once gone through a course of instruction, sometimes several years ago, presume to render "first aid" on the strength of what has been largely forgotten.

I have suggested, and I hope it may sooner or later be adopted, that students who take an interest in this work and have presented themselves for examination on three occasions shall have further power of periodical re-examination if they desire to keep themselves efficient in this, one of the most useful subjects which they can learn. The first-aid movement has rendered incalculable benefit to many a sufferer and to judge or to condemn it on account of one or two mistakes in the face of the numerous benefits conferred upon so many would be palpably unjust. The remedy lies in greater severity in the matter of examinations, as to whom certificates of efficiency are granted, and in the necessity of making those certificates which are gained only applicable to one year, or at the most two years, from the date of issue.

I am, Sirs, yours obediently,

SAMUEL Osborn,

Feb. 3rd, 1902

Chief Surgeon, Metropolitan Corps, St. John

To the Editors of THE LANCET.

SIRS,-If Mr. Walter G. Spencer will kindly re-peruse my letter in THE LaNCET of Jan. 18th, p. 194, he will see that I do not ask him to say what he would have done but "what the comrades ought to have done" in the sad case which I quoted. Mr. Spencer says: "It must be some kind of very large chaff-cutter to draw in both a man's legs-they would first be crushed by the rollers before being cut off. The result would not be different from a railway accident. Owing to the shock and the crushed ends of the arteries there would be no great arterial hæmorrhage." But the poor man died from hæmorrhage. We know that Mr. Spencer is an excellent surgeon and we feel sure that if he had been present "the rapid and efficient application of a tourniquet" would have been accomplished, and further, I believe that the man's life would have been saved. Mr. Spencer advises "that the instruction to an elementary class as regards such an accident should be that elevation and local pressure is to be applied at once and the tourniquet reserved until the patient is anæsthetised and the surgeon ready to explore the injury"; are there accidents which do require "the rapid and efficient application of a tourniquet" to save life? The St. John Ambulance Association says that there are, and you, Sirs, in your excellent leading article on this subject in THE LANCET of Jan. 25th, p. 238, also say there are; your words are pointed and cannot be misunderstood. You write: "To solve the problem of the correct treatment of hæmorrhage we must go back to general surgical principles. In the first place, we must distinguish the hrmorrhage after wounds of vessels in their continuity from that due to the complete removal of a part of a limb. In the latter case there is no room for doubt that a firmly applied tourniquet is the only method of rapidly controlling the extensive hæmorrhage which is generally present." It follows, therefore, that ambulance pupils must be taught how to apply a tourniquet rapidly and efficiently. Although I believe similar cases to the one referred to are not so infrequent as Mr. Spencer appears to me to think, the frequency has nothing to do with the matter. First-aiders have saved many a life, and may they continue their noble work, notwithstanding the discouragement which they have received from Mr. Spencer and a few others.

I am, Sirs, yours faithfully,

Ongar, Jan. 28th, 1902

J. B. G. GIDLEY-MOORE.

\section{THE TREATMENT OF METRORRHAGIA. To the Editors of THE LANCET.}

SIRs,-In his recent paper on the Uterine Curette, read before the Liverpool Medical Institution, an abstract of which appeared in THE LANCET of Jan. 25th, p. 229, Dr. H. Briggs adopted a very pessimistic attitude towards curettage-a proceeding which is frequently disappointing in its results to all gynæcologists. He mentioned one case of a woman who consulted him for a purulent condition of the uterus whom he had advised to relinquish local in favour of general hygienic treatment. In another case, where metrorrhagia recurred after curettage, he removed the uterus, there being no evidence brought before us of the existence of malignant or other grave disease. The impression I received from his paper was that Dr. Briggs was feeling his way to hysterectomy in the treatment of endometritis, or rather of metrorrhagia. The profession will be interested to learn whether this impression is a correct one, and how far Dr. Briggs suggests we should go in radical treatment for such conditions. The responsibility of surgeons in such cases is a very grave one, and the limits of justifiable operative treatment are, in my opinion, soon reached.

I am, Sirs, yours faithfully,

Liverpool, Jan. 25th, 1902. GEORGE A. HAWKINS-AMBLER.

\section{DEFICIENCY OF THE BILE-SALTS THE PROBABLE PREDISPOSING FACTOR IN TUBERCULOSIS AND FATTY FOODS CONTRA-INDICATED IN ITS TREATMENT.}

To the Editors of THE LANCET.

SIRS, - I have been for some years past of the opinion that the "bile-salts" played an important rôle with regard to tuberculosis, and now that the world is all agog with the subject of tuberculosis I wish to place my views and the results of $\mathrm{my}$ observations and deductions before the profession. It is well kwown that "tubercle bacilli" are difficult to grow on ordinary media, but by the addition of glycerine to the media a luxuriant growth is produced. I made a series of cultivations of tubercle bacilli in glycerine agar-agar and then endeavoured to cultivate them in glycerine agar-agar impregnated with the "bile-salts " (glycocholate and taurocholate of sodium). In many cases I failed to get any growth at all and when I did succeed the growth was very feeble indeed. I repeated this experiment with several other meda with the same result, Encouraged by these results I determined to try the effects of giving pig bile, "which most nearly resembles human bile," in large doses to a well-pronounced case of pulmonary tuberculosis ; and bearing in mind the fact that "bile" in the intestines saponifies as well as emulsifies fats and oils and produces glycerine as a by-product, I prohibited the use of all fatty foods, including cod-liver oil, cream, \&c., and kept the patient on a strictly but abundant nitrogenous diet with the idea of starving the "tubercle bacilli" of its congenial pabulum-i.e., "glycerine." The improvement was very marked, the cough improved, the evening temperature dropped, the night sweats discontinued, and a remarkable change occurred in the facial 